\title{
Abdominal CT Scan Based Estimation of Splenic Index and Splenic Volume in North Indian Adults
}

\author{
Govind Kumar ${ }^{\text {, Vinod Kumar² }}{ }^{2}$ Manisha Kumari³, Himanshu Mishra4, Suruthi T.I. ${ }^{5}$
}

${ }^{1}$ Department of General Medicine, Indira Gandhi Institute of Medical Sciences, Patna, Bihar, India. 2, 3, 4, 5 Department of Radiodiagnosis, Indira Gandhi Institute of Medical Sciences, Patna, Bihar, India.

\section{ABSTRACT}

\section{BACKGROUND}

Exposure of various tropical infections and infestations like tuberculosis, filariasis, malaria, anemia, kala-azar and poor sanitation are major health concerns in Bihar and it's neighboring state. Spleen size increases in several other diseases e.g., metabolism or storage disorder, malignancies and hematological disorders. Determining the normal parameters of spleen is essential for assessment of splenomegaly in routine ultrasonography (USG) or in the computed tomography (CT) scan. In this study, we wanted to estimate the CT based measurement of splenic dimensions in various planes, splenic index (linear dimension) and splenic volume and also to estimate the relationship of splenic index and splenic volume with age, gender and other splenic dimensions.

\section{METHODS}

It was a retrospective study and data was collected from January 2019 to December 2019. A total of 154 cases (including both genders) of age range 18 - 60 years were collected from the vitrea system (Vitrea software used for the 3-D assessment of splenic volume) and clinical data was collected from the medical record section. CT scan data of only those patients were included who had the clinical history of pain in abdomen, abdominal trauma or other diseases not affecting the spleen. Various measurements including splenic length and thickness at hilum and maximum thickness in axial view and height (maximum interpolar and true vertical height) in coronal views were recorded.

\section{RESULTS}

154 cases including both gender and age range of $18-60$ years were included in our study. There were 60 males and 94 females. The average age of the male and female patients was $45.93+/-15.19$ years and $45.87+/-15.12$ years respectively. The mean splenic dimensions were $9.03+/-1.49 \mathrm{~cm}$ in length (axial view), $3.69+/-0.05$ $\mathrm{cm}$ thickness at hilum (axial view) and $9.05+/-2.23 \mathrm{~cm}$ maximum craniocaudal length and $7.9+/-2.96 \mathrm{~cm}$ true vertical length (coronal view). Mean splenic index and mean splenic volume were $340.30+/-107.39 \mathrm{~cm} 3$ and $227.02+/-62.22 \mathrm{~cm} 3$ respectively. There was statistically significant correlation between splenic volume and maximum craniocaudal length $(\mathrm{r} 2=0.4848, \mathrm{P}=0.001)$, maximum axial length ( $\mathrm{r} 2=0.4765, \mathrm{P}<0.001)$ and true vertical length $(\mathrm{r} 2=0.3142, \mathrm{P}=0.001)$ with $95 \%$ confidence interval. For all splenic measurements, there was stronger correlation with maximum craniocaudal length followed by maximum axial length. However, there was no statistically significant correlation either of splenic volume with age in either gender $(\mathrm{r} 2=0.019, \mathrm{P}=0.043)$ or splenic index with age in either gender present $(\mathrm{r} 2=0.016, \mathrm{P}=0.059)$.

\section{CONCLUSIONS}

Maximum splenic length both in coronal (craniocaudal) and axial sections are positively and strongly correlated with splenic volume and splenic index but age of the individuals doesn't show any correlation either with the splenic volume or with splenic index. Hence, a regional reference of splenic parameters was established with a slightly different range of values reported previously.

\section{KEY WORDS}

Splenic Volume, Splenic Index, Computed Tomography
Corresponding Author: Dr. Manisha Kumari, B-502 Manju Vatika, Gola Road, Bailey Road, Danapur, Patna - 801503, Bihar, India. E-mail: minikishore79@gmail.com

DOI: $10.14260 / j e m d s / 2021 / 561$

How to Cite This Article:

Kumar G, Kumar V, Kumari $M$, et al. Abdominal CT scan based estimation of splenic index and splenic volume in north Indian adults. J Evolution Med Dent Sci 2021;10(33):2749-2753, 10.14260/jemds/2021/561

Submission 16-05-2021, Peer Review 11-07-2021, Acceptance 18-07-2021, Published 16-08-2021.

Copyright (c) 2021 Govind Kumar et al. This is an open access article distributed under Creative Commons Attribution License [Attribution 4.0 International (CC BY 4.0)] 


\section{BACKGROUND}

Spleen is a lymphoid and largest reticulo-endothelial organ and site for destruction of red blood cells (RBC). Usually, normal spleen weighs $150-200 \mathrm{~g}$ and $10.9+/-1.4 \mathrm{~cm}$ long, $4.0+/-0.45 \mathrm{~cm}$ deep and $6.8+/-0.71 \mathrm{~cm}$ in diameter. Some say that, for daily routine practice a value of $10 \mathrm{~cm}$ should be used for the upper limit of normality for calculations of splenic length as it is easier to remember. Some radiologist also thought that if spleen touches the left lobe of liver, then it should be considered as splenomegaly; however, this proved to be statistically insignificant. It is a concavo-convex structure with convex outer margin having ribs impressions over it. ${ }^{1}$ There is a wide range of normal spleen size values that is mentioned in different literature in different regions of the world. This makes the establishment of the normal values more difficult.

Spleen is not palpable till it increases two to three times normal. Reliability of clinical palpation is often imprecise as normal spleen is not palpable and a non-palpable spleen is not always normal. ${ }^{2}$ Exposure of the various tropical infections and infestations like tuberculosis, filariasis, malaria, anaemia, kala-azar and poor sanitation are the major health concerns in Bihar and it's neighboring state. Spleen being the reticuloendothelial system and first defense organ, it's size increases in the exposed person in comparison to the non-exposed. Spleen size also increases in several other diseases e.g. metabolism or storage disorder, malignancies and hematological disorders. ${ }^{3}$

There are various radiological investigations to identify and to measure splenic volumes. They are abdominal radiography (prior to the development of sonography), ultrasonography, computed tomography, magnetic resonance imaging (MRI) and radionuclide scans. ${ }^{1,4}$ Out of these, ultrasonography and computed tomography are most commonly used and reliable radiological investigation tools for intra-abdominal organs.

Splenic index and splenic volumes were measured by several authors in different countries. Splenic index (SI) is a research tool and used as an indicator in malaria surveillance. It is measured by multiplying length, width and thickness.5,6 Lackner et al. describe a splenic index using a combination of the width, thickness and length of the spleen as a numeric measure of splenomegaly, with an upper limit of $480 \mathrm{~cm} 3$ for normal spleen. ${ }^{7} \mathrm{~A}$ high splenic index is usually of no concern. However, a low index indicates compromised immune system which makes individual susceptible to various infections like malaria, filaria etc.

Several studies have been done, based on sonography of the abdomen to measure linear dimension of splenic length, width and thickness with upper limit of splenic volume 314.5 cm3. ${ }^{8}$ Volume estimation by 2D USG is usually not accurate because of several limitations leading to difficulty in completing scanning the entire organ due to the presence of overlying structures such as bone, bowel gas or kidneys.

Abdominal CT examination is more accurate than ultrasonography in measuring abdominal organs because of lack of the above drawback. Volumetric measurements (multiplanar reconstruction techniques) are most accurately obtained on CT or MRI and is more accurate than the 2D USG.9,10

\section{METHODS}

It is a retrospective study and has been done in the Department of Radiodiagnosis, Indhra Gandhi Institute of Medical Science, Patna, Bihar. The CT scan data was collected from January 2019 to December 2019 (12 months duration).

A total of 154 cases (including both genders) of age range 18 - 60 years were collected from the Vitrea System (Vitrea software and were used for the 3-D assessment of splenic volume) and clinical data was collected from the medical record section. CT scan data of only those patients was included who had the clinical history of pain in abdomen, abdominal trauma or other diseases not affecting the spleen. Patients whose spleen looked abnormal on CT e.g. focal or diffuse lesions were excluded from the study. Other diseases [e.g. hematological disorder, abdominal malignancies, infection, cirrhosis, portal hypertension, splenic space occupying lesion (SOL) and autoimmune disease] that affected the spleen were also excluded after clinical, laboratory and imaging evidence.

Technical parameters were $120 \mathrm{Kv}$ potential, $120 \mathrm{~mA}$ tube current and $5 \mathrm{~mm}$ slice thickness with various reconstruction techniques. Pre-contrast and post-contrast images were obtained. Spleen were evaluated in the axial, sagittal and coronal plane. Various measurements including splenic length and thickness at hilum and maximum thickness in axial view and height (maximum interpolar/oblique length and true vertical height) in coronal views were recorded.

\section{Statistical Analysis}

All the data were recorded in the MS Excel sheet and were analyzed by using analysis tool pak software. Linear Pearson's correlation coefficient was used to assess the strength of correlation between various splenic dimensions (along with coefficient) and splenic volume/index. Regression analysis and student t-test was used to compare the means. Multiple regression analysis was applied.

\section{RESULTS}

One hundred and fifty four cases with age range of $18-60$ years were included in our study. There were 60 males (38.96\%) and 94 females (61.04\%). More number of individuals present in the age group of $28-57$ years constituted $62.99 \%$ all together followed by 18 - 28 years of age.

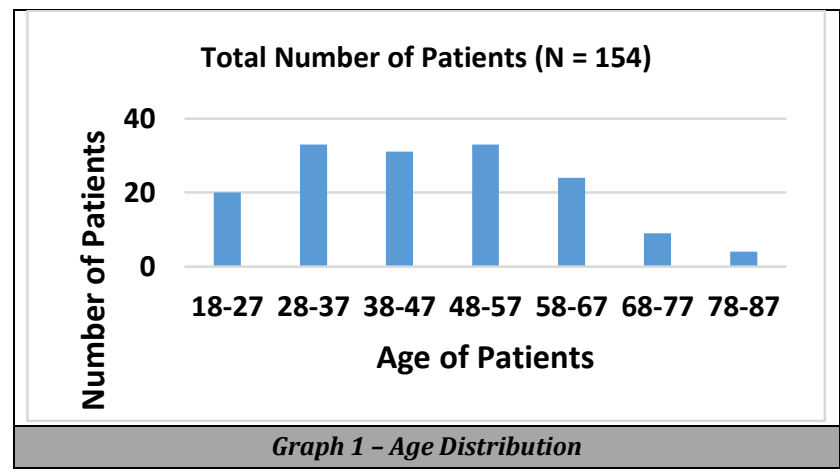




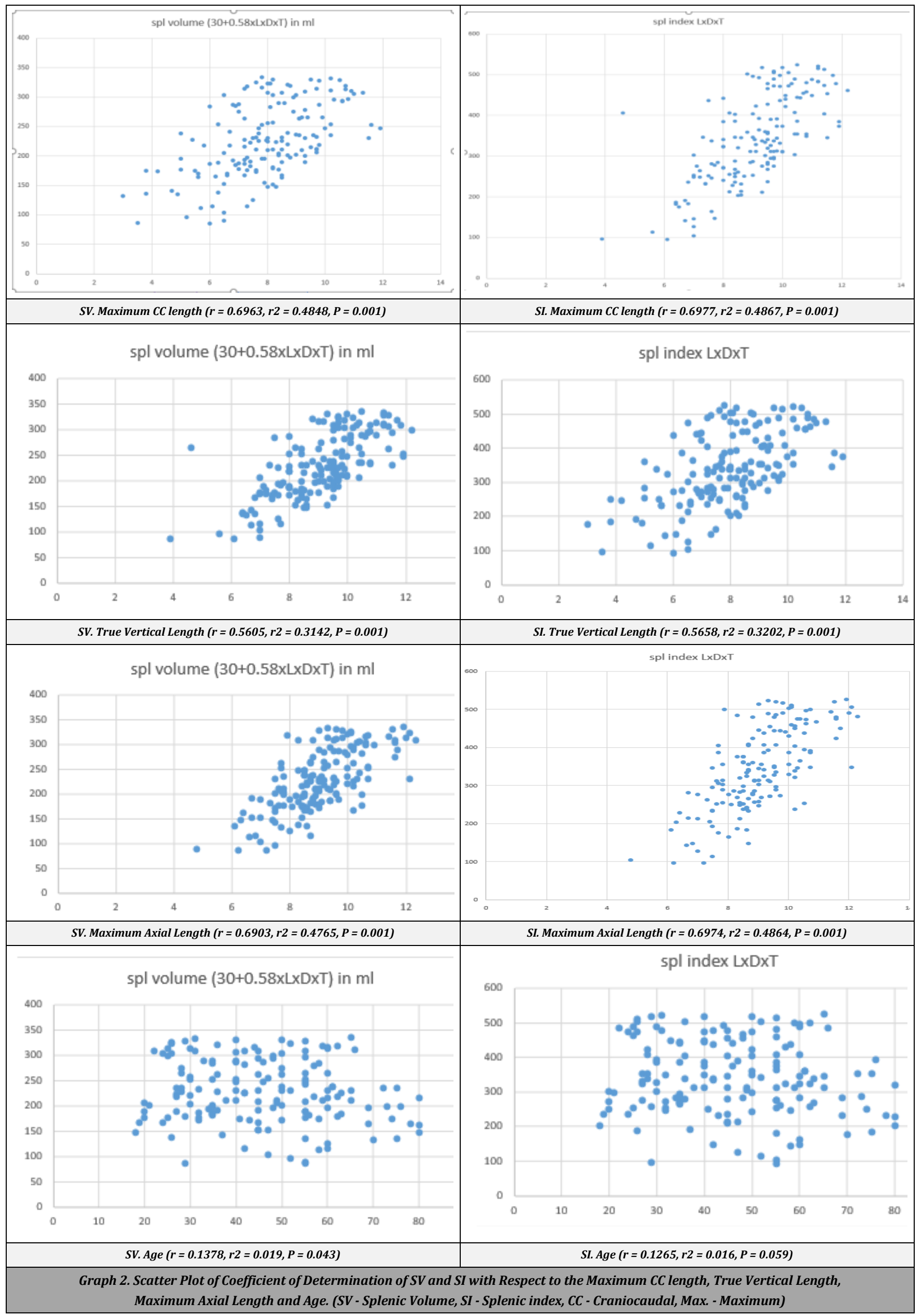




\begin{tabular}{|c|c|c|c|}
\hline Parameters & Total N = 154; Range $($ Mean +/- SD) & Female $\mathrm{N}=94 ;$ Range(Mean +/- SD) & Male N = 60; Range (Mean +/- SD) \\
\hline Age (in years) & $45.79+-15.1818-80$ & $45.87+-15.1219-80$ & $45.93+-15.1918-80$ \\
\hline Max. axial length (in cm) & $9.03+-1.364 .8-12.3$ & $8.77+-1.364 .8-12.1$ & $9.44+-1.366 .2-12.3$ \\
\hline Max. axial thickness (in cm) & $3.93+-0.691 .5-5.8$ & $3.91+-0.691 .5-5.7$ & $3.97+-0.692 .2-5.8$ \\
\hline Max. axial thickness at hilum (in $\mathrm{cm}$ ) & $3.69+-0.662 .3-5.7$ & $3.63+-0.672 .3-5.7$ & $3.77+-0.662 .4-5.1$ \\
\hline Max. CC length (in cm) & $9.05+-1.493 .9-12.2$ & $8.6+-1.493 .9-11.9$ & $9.35+-1.494 .6-12.2$ \\
\hline True vertical / CC length (in cm) & $7.9+-1.723-11.9$ & $7.78+-1.723-11.9$ & $8.23+-1.724 .7-11.3$ \\
\hline Splenic index (SI) (in cm3) & $340.3+-107.3995-525$ & $322.28+-107.4196-513$ & $368.53+-107.6395-525$ \\
\hline Splenic volume (SV) (in $\mathrm{cm} 3$ ) & $227.02+-62.2285-334$ & $216.98+-62.2386-328$ & $242.75+-62.3685-334$ \\
\hline Splenic weight (SW) (in g) & $238.34+-65.3889-351$ & $227.8+-65.3990-344$ & $254.87+-65.5388-351$ \\
\hline
\end{tabular}

\begin{tabular}{|c|c|c|c|}
\hline & Female $(\mathrm{N}=94)$ & Male $(\mathrm{N}=60)$ & P Value $(>0.001)$ \\
\hline Mean splenic index (SI) & $340.98(+-107.42)$ & $340.30(+-107.26)$ & 0.059 \\
\hline Mean splenic volume (SV) & $227.41(+-62.26)$ & $227.02(+-62.21)$ & 0.043 \\
\hline
\end{tabular}

The mean age was $45.79+/-15.18$ years. The average age of the male and female patients was $45.93+/-15.19$ years and $45.87+/-15.12$ years respectively. The mean splenic dimensions were $9.03+/-1.49 \mathrm{~cm}$ in length (axial view), 3.93 $+/-1.72 \mathrm{~cm}$ in maximum thickness and $3.69+/-0.05 \mathrm{~cm}$ thickness at hilum (axial view). Maximum craniocaudal (CC) length was $9.05+/-2.23 \mathrm{~cm}$ and true vertical length was 7.9 $+/-2.96 \mathrm{~cm}$ in coronal view. Mean splenic index (SI) and mean splenic volume (SV) were $340.30+/-107.39 \mathrm{~cm}^{3}$ and $227.02+/-62.22 \mathrm{~cm}^{3}$ respectively (Table 1 ). Mean splenic weight was $238.34+/-65.38$ g. There was no significant difference of SI and SV noted between male and female (Table 2).

Scatter plot in Graph 2 indicated that, coefficient of determination (r2) among splenic volume and splenic index with respect to maximum CC length, true vertical length and maximum axial length showed moderate positive linear relationship and this correlation was statistically significant $(\mathrm{P}<0.001)$. However, splenic volume and splenic index showed a weak relationship with age $(\mathrm{P}>0.043$ and $\mathrm{P}>$ 0.059 respectively for SV and SI) and was not statistically significant.

\section{DISCUSSION}

In this study, we found that there were 60 males $(38.96 \%)$ and 94 females (61.04\%). Mean age was $45.79+/-15.18$ years. The mean age of female and male was $45.87+/-15.12$ years and $45.93+/-15.19$ years respectively. Iwona Kucybala et al. showed that the mean age was $58.8+/-15.5$ years. They also showed that $48.5 \%$ and $51.5 \%$ population were female and male respectively. ${ }^{11}$ Ogbeide Ehimwenma et al. showed that the mean age of female and male was $29.7+/-9.0$ years and $32.4+/-9.2$ years respectively. ${ }^{12}$

For female, the mean splenic craniocaudal length, thickness and volume were $10.1+/-0.7 \mathrm{~cm}, 4.0+/-0.4 \mathrm{~cm}$ and $153+/-33.2 \mathrm{~cm} 3$ respectively. The corresponding values in male were $11.1+/-0.9 \mathrm{~cm}, 4.4+/-0.5 \mathrm{~cm}$ and $202+/-49.4$ $\mathrm{cm} 3$ respectively showing increased parameters in male. Ogbeide Ehimwenma et al. did ultrasound based study to determine splenic dimensions in 200 Nigerian adults $(20$ - 60 years), for the female, the mean splenic craniocaudal length, thickness and volume were $10.1+/-0.7 \mathrm{~cm}, 4.0+/-0.4 \mathrm{~cm}$ and $153+/-33.2 \mathrm{~cm} 3$ respectively and the corresponding values in male were $11.1+/-0.9 \mathrm{~cm}, 4.4+/-0.5 \mathrm{~cm}$ and 202 $+/-49.4 \mathrm{~cm} 3$ respectively. ${ }^{12}$ Kaneko J et al. found that the mean volume was $112 \mathrm{~cm} 3$, ranging from 32 to $209 \mathrm{~cm} 3 .{ }^{13}$
Mean splenic index (SI) was $340.30+/-107.39 \mathrm{~cm} 3$ in our study. Adil Asgar et al. showed that the mean SI was $494.82+$ /- 226.83.14 L. Grissom calculated and adjusted his upper normal value to 425 - $455 \mathrm{~cm} 3.15$ Prince Kapoor et al. calculated the mean splenic index as $342.62 \mathrm{~cm} 3 .{ }^{16}$ Strijk et al. had measured the splenic index and gave a mean value of $449 \mathrm{~cm} 3$ on European population which is considerable higher than the value of our study. ${ }^{17}$ According to Grissom and Shintr, upper normal value was $425-450 \mathrm{~cm} 3 .{ }^{15}$ Jong et al. defined the upper limit of normal as $725 \mathrm{~cm} 3$ and mean value of $395+/-163 \mathrm{~cm} 3$ in their study on 111 subjects which was again more than our findings. ${ }^{18}$

There was statistically significant correlation between splenic volume and maximum craniocaudal length $\left(\mathrm{r}^{2}=\right.$ 0.4848, $\mathrm{P}=0.001)$, maximum axial length $\left(\mathrm{r}^{2}=0.4765, \mathrm{P}<\right.$ $0.001)$ and true vertical length $\left(\mathrm{r}^{2}=0.3142, \mathrm{P}=0.001\right)$ with $95 \%$ confidence interval. For all splenic measurements, there was stronger correlation with maximum craniocaudal length followed by maximum axial length. Iwona Kucybala et al. showed that the strongest correlation of the splenic volume was detected for maximum height $\left(\mathrm{r}^{2}=0.804\right.$; $\left.\mathrm{P}<0.05\right)$, followed by true vertical height. ${ }^{11}$

However, there was no statistically significant correlation either of splenic volume with age in either gender $\left(r^{2}=0.019\right.$, $\mathrm{P}=0.043$ ) or splenic index with age in either gender present $\left(r^{2}=0.016, P=0.059\right)$ in our study. Ardene Harris et al. in their study in 2010 showed that the splenic volume has negative correlation with age of the individual. ${ }^{19}$ However, Kaneko J et al. showed in their study that there was significant correlation of splenic volume with age but not with gender. ${ }^{13}$

Mean splenic weight was $238.34+/-65.38 \mathrm{~g}$ in our study, which was at the upper limit of normal range. P. Prassopoulos et al. found that the average splenic weight was $150 \mathrm{~g}$ (range $100-250 \mathrm{~g}$ ).

\section{CONCLUSIONS}

Determination of normal parameters of spleen is essential for it's assessment in routine ultrasonography or in the CT scan. The automatically contouring software as well as splenic volume calculator can be used to calculate the splenic volume, splenic index and splenic weight in certain cases where splenic involvement is suspected by various disease processes. Maximum splenic length both in coronal (craniocaudal) and axial sections are positively and strongly 
correlated with splenic volume and splenic index, but age of the individuals doesn't show any correlation either with the splenic volume or with splenic index. Hence, a regional reference of splenic parameters was established. We also conclude that the mean splenic index and mean splenic volume in our study population lies below the European, American and Nigerian population and is less than the normal value $480 \mathrm{~cm} 3$. This probably makes our population more vulnerable to tropical infections.

Data sharing statement provided by the authors is available with the full text of this article at jemds.com.

Financial or other competing interests: None.

Disclosure forms provided by the authors are available with the full text of this article at jemds.com.

We are very thankful to Soni (Radiographer) and Raju Gupta, for the technical help and unconditional support.

Author's Contribution - 1) Govind Kumar - Conceptualization and Methodology, Reviewing and editing, 2) Manisha Kumari - Data collection, Data analysis and original draft preparation, 3) Vinod Kumar - Reviewing and editing, 4) Himanshu Mishra - Data curation \& compilation and 5) Suruthi T.I. - literature search.

\section{REFERENCES}

[1] Benter T, Kluhs L, Teichgraber U. Sonography of the spleen. J Ultrasound Med 2011;30(9):1281-93.

[2] Kumar L, Bansal AK. Splenomegaly: a clinical approach. In: Munjal YP, Sharma SK, eds. Api textbook of Medicine. Mumbai, India: The Association of Physicians of India 2012: p. 926-7.

[3] Lamb PM, Lund A, Kanagasabay RR, et al. Spleen size: How well do linear ultrasound measurements correlate with three dimension CT volume assessments? $\mathrm{Br}$ J Radiol 2002;75(895):573-7.

[4] Sutherland T, Temple F, Galvin A, et al. Contrastenhanced ultrasound of the spleen: an introduction and pictorial essay. Insights Imaging 2011;2(5):515-24.

[5] De Odorico I, Spaulding KA, Pretorius DH, et al. Normal splenic volumes estimated using three dimensional ultrasonography. J Ultrasound Med 1999;18(3):231-6.

[6] Kardel T, Holm HH, Rasmussen SN, et al. Ultrasonic determination of liver and spleen volumes. Scandinavian Journal of Clinical and Laboratory Investigation 1971;27(2):123-8.

[7] Lackner $\mathrm{K}$, Brecht $\mathrm{G}$, Janson $\mathrm{R}$, et al. The value of computer tomography in the staging of primary lymphnode neoplasm. Rofo 1980;132(1):21-30.
[8] Prassopoulos P, Daskalogiannaki M, Raissaki M, et al Determination of normal splenic volume on computed tomography in relation to age, gender and body habitus. European Radiology 1997;7(2):246-8.

[9] Dick R. The liver and spleen. In: Sutton D, edr. Textbook of Radiology and Imaging. London: Churchill Livingstone 1998: p. 981-1028.

[10] Breiman RS, Beck JW, Korobkin M, et al. Volume determinations using computed tomography. AJR Am J Roentgenol 1982;138(2):329-33.

[11] Kucybala I, Ciuk S, Teczar J. Spleen enlargement assessment using computed tomography: which coefficient correlates the strongest with the real volume of spleen? Abdomenal Radiology (NY) 2018;43(9):245561.

[12] Ehimwenma 0, Tagbo MT. Determination of normal dimension of the spleen by ultrasound in an endemic tropical environment. Niger Med J 2011;52(3):198-203.

[13] Kaneko J, Sugarwara Y, Matsui Y, et al. Normal splenic volume in adults by computed tomography. Hepatogastroenterology 2002;49(48):1726-7.

[14] Asghar A, Naaz S, Agrawal D. Estimation of standard splenic index (SI) in Indian population: a CT scan based study. Indian Journal of Basic and Applied Medical Research 2014;3(2):332-7.

[15] Grissom L, Shintr. Splenic index. Message-ID: <3668BFIC.34C351F9@earthlink.net>and messageID<19981201162157.26188.00000693@ng13 7.aol.com>sci.d.radiology 1998. (Cited on 2011 July 17).

[16] Kapoor P, Tewari V, Sharma PK, et al. CT scan based evaluation of slenic index in patients from Lucknow and adjoining areas. J Anat Science 2018;26(2):65-8.

[17] Strijk SP, Boetes C, Bogman MJ, et al. The spleen in Non Hodgkin Lymphoma: diagnostic value of compited tomography. Acta Radiologica 1987;28(2):139-44.

[18] De Jong PA, van Ufford HMQ, Baarslag HJ, et al. CT and 18F - FDG PET for nin - invasive detection of splenic involvement in patients with malignant lymphoma. American Journal of Roentgenology 2009;192(3):74553.

[19] Harris A, Kamishima T, Hao HY, et al. Splenic volume measurements on computed tomography utilizing automatically contouring software and it's relationship with age, gender and anthropometric parameters. European Journal of Radiology 2010;75(1):e97-e101. 